control arm have an annual $x$ ray or nothing other than simple follow-up. The contamination rate for the control arm (ie, having a sneak chest radiograph or even a privately paid computed tomography) is not known, although this reached in excess of $50 \%$ in the chest radiograph versus nothing randomised controlled trial led by the Mayo Clinic in the 1950s.

Into this area of uncertainty comes a most interesting study with perhaps an intuitively obvious result from Silvestri et al in this month's issue of Thorax (see page 126)..$^{12}$ They carried out a telephone questionnaire on a nationwide sample of Americans aged $\geqslant 40$ years, identified by a random dialling telephone system. From 21000 households contacted, 2001 individuals were prepared to answer structured questions from a trained interviewer. What transpired was that smokers in the survey were significantly more likely than non-smokers to be male, nonwhite, less well educated and to report poorer health status or history of cancer, and also (in the US system) to be less able to identify a usual source of healthcare. When contrasting the attitude to screening for risk of disease, the current smokers were less likely than the nonsmokers to believe that early detection would result in a good chance of survival. The smokers were also less likely to consider undergoing a computed tomography for screening for lung cancer, and fewer current smokers believed that the risk of lung cancer or the accuracy of the test was an important factor in deciding whether to enter a screening programme. Even worse, only half of the current smokers would have chosen to opt for surgical removal of a screen-diagnosed cancer.

The authors of the paper are correct to conclude that there remain substantial obstacles to the implementation of a mass screening programme for lung cancer. Many of the problems have been outlined above, without mentioning the huge effect the organisation of such a programme would have on resource, equipment, radiographers, radiologists, surgeons and, not least, the funders. There is even a debate ongoing on the best design for such a programme. Also, with the rapidly improving technology around sophisticated pulmonary imaging, it is hard to see how a 5-year study can be set up without the means to incorporate newer imaging computer programs and other refinements as the study progresses. What about the role of positron emission tomography which is regarded as more sensitive and specific than computed tomography alone in determining the potential malignant nature of a lesion? On top of this are data suggesting that those who we would wish to be the primary targets to screening may be the most indifferent to its benefits and unwilling to participate. It would be of little use if the educated, affluent and interested were the only recepients of this expensive tool. However, despite all the negative arguments, the value of screening remains unproved and therefore continues as a very important issue in the management of lung cancer, and should be properly supported and researched until its value becomes clear.
Thorax 2007:62:105-106.

doi: $10.1136 /$ thx.2006.061309

Correspondence to: Professor S G Spiro, Department of Respiratory Medicine, University College Hospital, Grafton Way, London WCIE 6AU, UK; stephen.spiro@uclh.nhs.uk

\section{REFERENCES}

1 Hamilton W, Peters TJ, Round A, et al. What are the clinical features of lung cancer before the diagnosis is made? A population based case-controlled study. Thorax 2005;60: 1059-65.

2 Fontana RS, Sanderson DR, Woolner LB, et al. Lung cancer screening. The Mayo Program. J Occup Med 1986;28:746-50.

3 Marcus P, Bergstralh E, Fagerstrom R, et al. Lung cancer mortality in Mayo Lung Project: impact of extended follow-up. I Natl Cancer Inst 2000;92:1308-16.

4 Bach P, Kelly $M$, Tate $R$, et al. Screening for lung cancer. A review of the literature. Chest 2003; 123:72S-82S.

5 Henschke C, McCauley D, Yankelevitz D, et al. Early lung cancer detection project: overall design and findings from baseline screening. Lancet 1999;354:99-105

6 Sone S, Takashima S, Li F, et al. Mass screening for lung cancer with mobile spiral computed tomography scan. Lancet 1998;351:1242-5.

7 Sobue T, Moriyama N, Kaneko M, et al. Screening for lung cancer with low-dose helical computed tomography: anti-lung cancer association project. J Clin Oncol 2002;20:91 1-20.

8 Swensen S, Jett J, Sloan J, et al. Screening for lung cancer with low-dose spiral computed tomography. Am J Respir Crit Care Med 2002;165:508-13.

9 MacRedmond R, Logan PM, Lee M, et al. Screening for lung cancer using low dose CT scanning. Thorax 2004:59:237-41.

10 Swensen S, Jeft J, Hartman T, et al. Lung cancer xcreening with CT: Mayo Clinic experience. Radiology 2003:226:756-61.

11 Henschke Cl, Reeves AP, Shaham D, et al. CT screening for lung cancer. In:Textbook of prevention and detection of early lung cancer.Taylor and Francis, 2005: 187-204

12 Silvestri GA, Nietert PJ, Zoller J, et al. Attitudes towards screening for lung cancer among smokers and their non-smoking counterparts. Thorax 2006;62: 126-30.

\title{
Further evidence that the wealthier are healthier: negative life events and asthma-specific quality of life
}

\section{R J Wright}

\section{Association between psychological stress and asthma expression and morbidity}

n this issue of Thorax, Archea et al ${ }^{1}$ (see $p$ 139) add to the growing number of studies linking psychological stress to asthma expression and morbidity. To date, studies have reported an association between various measures of life stress and both the onset of asthma or precedent phenotypes ${ }^{23}$ and exacerbations of established disease. ${ }^{4-6} \quad$ Hypothesised mechanisms underlying the association between stress and asthma expression implicate reciprocal relationships between neural, hormonal and immunological pathways that have been extensively reviewed previously. ${ }^{78}$ Evidence demonstrating that psychological stress influences the expression of inflammatory cytokine patterns in patients with asthma or those at risk of developing the disease supports these theories. ${ }^{9}{ }^{10}$ Others have shown that physiological changes, including neuroimmune and genetic processes, may lead to differential responses to therapeutic interventions for asthma and atopic disorders. ${ }^{11}{ }^{12}$

The current work by Archea et al underscores that psychological factors may also be more indirect, albeit equally important, determinants of asthma 
morbidity by influencing how individuals perceive and manage their disease. They aimed to examine the relationship between negative life events (NLEs) and asthma-specific quality of life (AQoL), and also to understand the interrelationships among AQoL, asthma severity and socioeconomic status (SES). These crosssectional results show a relationship between the frequency of experiencing NLEs, a measure of psychological stress, and AQoL among 189 adults with asthma. Those experiencing a greater number of NLEs reported a worse AQoL, a relationship seen across all SES strata. The addition of sex, age, education and race in regression analyses had little effect on the significance of NLEs. When they stratified by income level and severity of asthma, some notable differences emerged. People with more severe disease reported worse AQoL across income strata regardless of the number of life events. Experiencing a higher frequency of NLEs was associated with poorer AQoL, although this relationship was evident with fewer NLEs in the lower income stratum. And finally, in the lowest income category, greater frequency of NLEs was associated with poorer AQoL across all strata of severity. Control for smoking in these analyses had no great influence on the outcome. Future studies examining these relationships in a longitudinal manner are needed to better delineate these associations.

By drawing attention to overlapping research in stress theory, social learning theory and health behaviour research, we may expand on the discussion started by Archea $e t a l^{1}$ as to why such differences might be observed. It has been proposed that the association between SES and health disparities may, partly, be determined by increased exposure to acute and chronic stress compounded by the presence of overburdened or absent social supports, psychological morbidity (ie, anxiety and depression) and lack of control over one's life. ${ }^{13-15}$ Research on stress has consistently documented that not only are NLEs experienced more frequently among people in lower SES positions but that they are also more strongly emotionally affected by adverse life events. ${ }^{16}$ Other literature suggests that support systems (eg, social supports and social networks) may serve as protective moderators of life stressors. ${ }^{17}$ However, groups with lower SES are disadvantaged in their likelihood of experiencing adverse events and also in coping resources they may have available. ${ }^{18}$

Moreover, ecological views on health recognise that individual-level health risks and behaviours have multilevel determinants, partly influenced by the social context within which individuals live. ${ }^{1920}$ Research has begun to explore how the degree of chronic stress is influenced by the characteristics of the communities in which we live. One type of chronic stress that has been investigated in relation to urban health in the US, for example, is neighbourhood disadvantage characterised by the presence of several community-level stressors including poverty, unemployment or underemployment, limited social capital or social cohesion, substandard housing, and high exposure rates to crime or violence. ${ }^{21}$ Such stress is chronic and can affect all individuals in a given environment regardless of their individual-level risks or life events experienced.

In our laboratory, we have considered exposure to violence in the community as a useful paradigm to understand how chronic social stressors derived from multiple levels may influence asthma burden. ${ }^{22}$ We showed an association between higher levels of community violence, conceptualised as an indicator of community-level stress, and increased caretaker-reported asthma symptoms among children aged 5-12 years enrolled in the Inner-City Asthma Study. ${ }^{6}$ In this study, caretaker-reported prevalence of violence in the community, frequency of other NLEs, perceived stress, unwanted thoughts and memories (rumination), caretaker behaviours (eg, keeping children indoors, smoking and medication adherence) and sociodemographic indicators (eg, income, employment, race or ethnicity and housing quality) were ascertained $(n=851)$. Increased frequency of exposure to violence in the communities predicted a greater number of asthma symptom days among the children in a graded fashion even after controlling for socioeconomic factors and housing dilapidation. This association was partly attenuated by controlling for the frequency of reported experiencing of other NLEs as well as perceived stress and behavioural differences, albeit the trend remained significant. It would be interesting to examine stress in such a multilevel framework in relation to quality of life.

Individuals facing cumulative challenges in poverty-stricken, high-crime, inner-city neighbourhoods ${ }^{23}$ may be most in need of stress buffers and, yet, the support provided by highly stressed network members may be compromised by the demands that these same people are facing. ${ }^{24-27}$ The costs of maintaining social networks in lower-income communities may outweigh their benefits-many parents find that protecting themselves and their children from neighbourhood dangers requires withdrawal from the community. ${ }^{28}$ These and other studies show that being a single parent in such environments may add a further burden. Single parenting and psychological distress have been linked by an unremitting succession of negative events, economic hardship, social isolation and heavy parenting responsibilities.

Then how might increased NLEs be linked to outcomes such as AQoL? When individuals confront environmental demands (life events), they appraise the event(s) as threatening or potentially overwhelming to their existing coping resources. If the events are viewed as taxing, and at the same time coping resources are inadequate, we perceive ourselves to be under stress or distress. Thus, lower-income groups with fewer coping resources and increased cumulative multilevel stress may theoretically be more overwhelmed in the face of fewer individual-level NLEs as reported by Archea et al. ${ }^{1}$ This perception may, in turn, result in negative emotional states, including anger, anxiety, depression and lower perceived control, which may influence health behaviours including important self-management strategies and adherence behaviours that may affect asthma expression and QoL. ${ }^{729}$ One caveat of this, as pointed out by these and other authors, is that negative affective states may influence both symptom reporting in asthma and QoL measures. ${ }^{30}$ This needs to be carefully considered in continued work in this discipline.

Although these relationships are complex, as noted earlier, studies such as those by Archea et al ${ }^{1}$ reported in this issue of Thorax may have considerable implications for asthma management and clinical guidelines. Recognising which groups are most vulnerable to the effects of stress, what stressors are most likely to influence asthma outcomes, paying particular attention to cumulative stressors, and implementing alternative modalities that reduce stress at the individual level may benefit asthma management. ${ }^{31}$ Understanding and responding to the complex factors that contribute to differences in exposure to environmental factors, including stress based on socioeconomic position on a broader scale (ie, at the population level), may contribute to reducing rising disparities in asthma morbidity worldwide. ${ }^{32}$

\section{Thorax 2007:62:106-108.}

doi: 10.1136/thx.2006.067926

Correspondence to: Dr R J Wright, Channing

Laboratory, Brigham \& Women's Hospital,

Harvard Medical School, 181 Longwood

Avenue, Boston, MA 02115, USA

rosalind.wright@channing.harvard.edu

Competing interests: None declared. 


\section{REFERENCES}

1 Archea C, Yen I H, Chen $\mathrm{H}$, et al. Negative life events and quality of life in adult asthma. Thorax 2006:62:139-46

2 Wright RJ, Cohen S, Carey V, et al. Parental stress as a predictor of wheezing in infancy: a prospective birth-cohort study. Am J Respir Crit Care Med 2002; 165:358-65.

3 Mrazek DA, Klinnert M, Mrazek PJ, et al. Prediction of early-onset asthma in genetically at-risk children. Pediatr Pulmonol 1999;27:85-94.

4 Sandberg S, Paton JY, McCann DC, et al. The role of acute and chronic stress in asthma attacks in children. Lancet 2000;356:982-7.

5 Sandberg S, Jarvenpaa S, Pentinen A, et al. Asthma exacerbations in children immediately following stressful life events: a Cox's hierarchical regression. Thorax 2005;59:1046-51.

6 Wright RJ, Mitchell H, Visness CM, et al. Community violence and asthma morbidity in the Inner-City Asthma Study. Am J Public Health 2004;94:625-32.

7 Wright R, Rodriguez M, Cohen S. Review of psychosocial stress and asthma: an integrated biopsychosocial approach. Thorax 1998:53:1066-74.

8 Wright RJ. Stress and atopic disorders. J Allergy Clin Immunol 2005;1 16:1301-6.

9 Chen E, Fisher EB, Bacharier $L B$, et al. Socioeconomic status, stress, and immune markers in adolescents with asthma. Psychosom Med 2003;65:984-2

10 Wright RJ, Finn PW, Contreras JP, et al. Chronic caregiver stress and lgE expression, allergeninduced proliferation, and cytokine profiles in a birth-cohort predisposed to atopy. J Allergy Clin Immunol 2004; 113:1051-7.

11 Miller GE, Chen E. Life stress and diminished expression of genes encoding the glucocorticoid receptor and $\beta 2$-adrenergic receptor in children with asthma. Proc Natl Acad Sci USA 2006;103:5496-501.

12 Ippoliti F, DeSantis W, Volterrani A, et al. Psychological stress affects response to sublingual immunotherapy in asthmatic children allergic to house dust mite. Pediatr Allergy Immunol 2006;17:337-45.

13 Marmot MG, Kogevinas M, Elston MA. Social/ economic status and disease. Annu Rev Pubicl Health 1987:8:111-35.

14 Williams D. Socioeconomic differentials in health: review and redirection. Soc Psychol $Q$, 1990;53:81-99.

15 Cohen S, Kaplan GA, Salonen JG. The role of psychological characteristics in the relation of socioeconomic status and perceived health. J App Soc Psychol 1999;29:445-68.

16 McLeod JD, Kessler RC. Socioeconomic status differences in vulnerability to undesirable life events. J Health Soc Behav 1990:31:162-72.

17 Cohen S, Gottlieb B, Underwood L. Social relationships and health. In: Cohen S, Underwood L Gottlieb B, eds. Measuring and intervening in socia support. New York: Oxford University Press, 2000

18 Kessler RC. Stress, social status, and psychological distress. J Health Soc Behav 1979;20:259-72.

19 Stokols D. Establishing and maintaining health environments: toward a social ecology of health promotion. Am Psychol 1992;47:6-22.

20 Taylor S, Repetti R, Seeman T. Health psychology: what is an unhealthy environment and how does it get under the skin? Annu Rev Psychol 1997;48:41 1-47.

21 Attar BK, Guerra NG, Tolan PH. Neighborhood disadvantage, stressful life events, and adjustment in urban elementary-school children. J Clin Child Psychol 1994;23:391-400.

22 Wright RJ. Health effects of socially toxic neighborhoods: the violence and urban asthma paradigm. Clin Chest Med 2006;27:413-21.
23 Klebanov PK, Brooks-Gunn J, Chase-Lansdale PL, et al. Are neighborhood effects on young children mediated by features of the home environments? In: Brooks-Gunn J, Duncan GJ, Aber JL, eds. Neighborhood poverty. New York: Russell Sage Foundation, 1997:119-45.

24 Belle D. The impact of poverty on social networks and supports. Marriage Fam Rev 1982;5:89-103.

25 Brodsky AE, Makingit J. The components and process of resilience among urban, AfricanAmerican, single mothers. Am J Orthopsychiatr 1999:69:148-60.

26 Coulton CJ, Pandey S. Geographic concentration of poverty and risk to children in urban neighborhoods. Am Behavl Scit 1992;35:238-57.

27 Ceballo R, McLoyd VC. Social support and parenting in poor, dangerous neighborhoods. Child Dev 2002;73:1310-21.

28 Jarrett RL. Voices from below: the use of ethnographic research for informing public policy. In: Mercier JM, Garasky S, Shelly MC, eds. Redefining family policy: implications for the 21 st century. Ames: lowa State University Press, 2000.

29 Adams RJ, Wilson DH, Taylor AW, et al. Psychological factors and asthma quality of life: a population based study. Thorax 2004;59:930-5.

30 Price MR, Bratton DL, Klinnert MD. Caregiver negative affect is a primary determinant of caregiver report of pediatric asthma quality of life. Ann Allergy Asthma Immunol 2002;89:572-7.

31 Wright RJ. Alternative modalities for asthma that reduce stress and modify mood states: evidence for underlying psychobiologic mechanisms. Ann Allergy Asthma Immunol 2004;92:1-6.

32 Wright RJ, Fisher E. Putting asthma into context: community influences on risk, behavior, and intervention. In: Kawachi I, Berkman L, eds. Neighborhoods and health. Oxford: Oxford University Press, 2003. 